\title{
CARACTERISTICAS GEOLÓGICAS E ORIGEM DOS CONGLOMERADOS DIAMANTÍFEROS DAS REGIŌES DE DIAMANTINA (MESOPROTEROZÓICO) E DE ROMARIA (CRETÁCEO SUPERIOR), MINAS GERAIS।
}

\author{
M.L.S.C.Chaves ${ }^{2}$ \& D.P.Svisero ${ }^{3}$
}

PALAVRAS-CHAVE: Diamantina, Romaria, diamante, conglomerado.

CHAVES, M.L.S.C.; SVISERO, D.P. (1993) Características geologicas e origem dos conglomerados diamantiferos das regiǒes de Diamantina (Mesoproterozóico) e de Romaria (Cretáceo Superior), Minas Gerais, Bol.IG-USP, Sér,Cient., 24:49-57.

\section{RESUMO}

Săo descritos e comparados os principais paràmetros estratigráficos, sedimentológicos, estruturais e mineralógicos dos conglomerados diamantiferos que ocorrem na região de Romaria (Cretáceo Superior), situada no sudoeste do Estado de Minas Gerais, com os do Distrito de Diamantina (Mesoproterozói$\mathrm{co}$ ), localizada no centro-norte do mesmo estado. Demonstra-se que, apesar do amplo intervalo de tempo envolvendo a deposiçäo dos conglomerados nesses dois locais, existem diversos aspectos que indicam similaridades entre eles. Ambos foram depositados em leques aluviais, indicando áreas-fonte continentais tectonicamente ativas. As condiç̧̄es de rápido soerguimento e erosão provavelmente nivelaram as rochas matrizes primárias, ainda desconhecidas, às suas zonas críticas de esterilidade. $\mathrm{O}$ teor em diamantes é baixo nos conglomerados. variando de 0,01 a $0,07 \mathrm{ct}^{3} \mathrm{~m}^{3}$. Dados disponiveis até o presente momento mostram que a principal diferença entre os dois locais é a ausência de minerais indicadores de kimberlitos tais como $\mathrm{Cr}$-piropo e ilmenita magnesiana entre os pesados da regiảo de Diamantina.

\section{ABSTRACT}

Diamond-bearing conglomerates occur in the Sopa Brumadinho Formation of the Middle Proterozoic Espinhaço Supergroup and have been mined in the area of Diamantina, central Minas Gerais, since 1725. On the other hand, similar deposits occur at the base of the Upper Cretaceous Uberaba Formation in the area of Romaria in western Minas Gerais and have been mined since the end of the last century. Although these occurrences differ in age by almost $1.5 \mathrm{Ga}$, they display several geological characteristics that point to their deposition in fans developed in tectonically active areas. In addition, their diamond content is low, ranging from 0.01 up to $0.07 \mathrm{ct} / \mathrm{m}^{3}$. Apparently the most remarkable difference between them is the absence of kimberlitic indicator minerals such as $\mathrm{Cr}$-pyrope gamet and $\mathrm{Mg}$-ilmenite among the heavies in the Diamantina District.

\footnotetext{
1 Trahalho parcialmente financiado pelo CNPq a M.L. S.C.Chaves atravis dos processos $401.958 / 88$ e 400.92490.

${ }^{2}$ Departamento de Geologia, IOCNFMG, Belo Horizonte, Brasil.

${ }^{3}$ Departamento de Mineralogia e Petrologia, Instituto de Geociências/USP, Säo Paulo, Brasil.
} 


\section{INTRODUÇÃo}

Conglomerados diamantiferos ocorrem em Minas Gerais associados principalmente a duas unidades litoestratigráficas de áreas e idades distintas: (1) no centro-norte do Estado, a Formação Sopa Brumadinho (Supergrupo Espinhaço) é de idade mesoproterozóica e, (2) no sudoeste do Estado, os conglomerados basais da Formação Uberaba pertencem ao Cretáceo Superior. Estas formações definem duas importantes provincias diamantiferas brasileiras: a do Espinhaço e a do Alto Paranaiba, respectivamente.

Apesar do amplo intervalo de tempo (cerca de 1,5 Ga) envolvendo a deposição dos conglomerados nestes dois locais, existem diversas semelhanças entre tais depósitos, conforme previamente descrito em Chaves \& Svisero (1992).

O presente estudo tem como objetivo a descrição dos principais parâmetros estratigráficos, sedimentológicos e estruturais comparando os depósitos em ambas as localidades, constatando que processos genéticos afins ocorreram nesses diferentes tempos. Os índices mineralógicos são bem conhecidos na área de Romaria, porém muito pouco estudados nos conglomerados de Diamantina, sendo atualmente objeto de pesquisa por um dos autores (MLSCC) em sua Tese de Doutoramento.

\section{O DISTRITO DIAMANTÍFERO DE DIAMANTINA}

O Distrito Diamantifero de Diamantina, conhecido desde as descobertas pioneiras do inicio do século dezoito, está situado na Serra do Espinhaço Meridional, na porção centro-norte de Minas Gerais. Esta região é geologicamente constituída por espessas sequeências meta-areniticas, pertencentes ao Supergrupo Espinhaço (Fig. 1).

O Supergrupo Espinhaço, na área

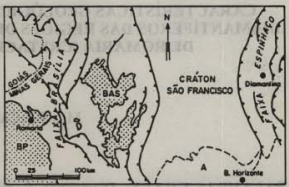

Figura 1 - Esboço geológico simplificado situando as áreas estudadas (Diamantina e Romaria). BP Bacia do Paraná; BAS - Bacia Alto Sanfranciscana; A - Rochas Arqueanas (modificado de Schobbenhaus et al., 1984).

onde ocorrem os principais depósitos diamantíferos, está representado por sua unidade inferior constituindo o Grupo Diamantina (Dossin et al., 1990). Este, por sua vez, é integrado pelas formaçōes São João da Chapada, Sopa Brumadinho e Galho do Miguel, da base para o topo (Fig. 2). O metamorfismo que afetou o Supergrupo Espinhaço é do fäcies xistos verdes.

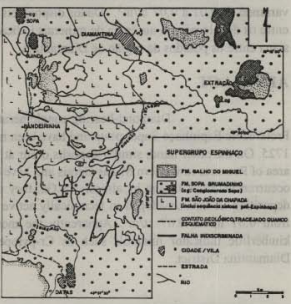

Figura 2 - Geologia da regiăo de Diamantina ressaitando as áreas de ocorréncia do Conglomerado Sopa. 
A Formação Sopa Brumadinho caracteriza-se por rápidas variaçōes faciológicas laterais e verticais, que indicam mudanças enérgicas nas condições paleoambientais de deposição dos seus litotipos (Pflug, 1965; Chaves et al., 1985). Afloram na base da unidade, localmente, metapelitos possivelmente de origem lagunar, resultantes da regressão do mar no final da deposição da Formação São João da Chapada. Esta sedimentação pelitica é recoberta por possantes pacotes metareniticos, via de regra grossos, típicos de depósitos continentais fluviais braided (Garcia \& Uhlein, 1987). A esta associação faciológica pertencem os conglomerados diamantiferos da Formação Sopa Brumadinho.

O topo da sequêencia é formado por depósitos que representam uma transgressāo marinha, aparecendo tipos conglomeráticos que localmente são diamantíferos, como na Mina do Campo Sampaio. São característicos desta fase deposicional, sedimentos pelíticos intercalados com brechas e paraconglomerados (depósitos de debris flow), constituindo o Membro Campo Sampaio (Fogaça \& Abreu, 1982). Com-pletando o ciclo deposicional que define o Grupo Diamantina, os metarenitos eólicos da Formação Galho do Miguel recobrem tanto as várias unidades da Formação Sopa Brumadinho, como também a Formação São João da Chapada e as rochas granito-gnáissicas do Complexo Basal, definindo deste modo, uma discordância erosiva regional (Fig. 2).

No âmbito da Província Diamantifera do Espinhaço, o Distrito de Diamantina destaca-se, historicamente, como o maior produtor de diamantes do Brasil (Chaves \& Uhlein, 1991). Ao contrário do Alto Paranaiba, não existem aí registros de kimberlitos ou de lavas ultrabásicas alcalinas, tornando o problema da origem do diamante mais complexo. Na região de Diamantina, o diamante é encontrado nas rochas conglo- meráticas da Formação Sopa Brumadinho. A natureza clástica desta unidade revela que o diamante é reciclado, sendo suas fontes primárias desconhecidas na região.

\section{O CONGLOMERADO SOPA}

Os conglomerados tipo "Sopa" (Fig. 2) afloram regionalmente sobre uma faixa linear com cerca de $100 \mathrm{~km}$ de comprimento (N-S). Essa faixa coincide aproximadamente com a porção axial da Serra do Espinhaço, explicando assim a notável distribuição aluvionar cenozóica dos depósitos diamantíferos. Segundo Chaves \& Uhlein (1991), na região de Diamantina, tais rochas estão agrupadas em quatro campos mineralizados com afinidades características, assim distribuídos: 1) São João da Chapada - Campo Sampaio, 2) Sopa-Guinda, 3) Extração e, 4) Datas. A espessura dos depósitos varia desde cerca de 10 metros, no Campo de Sopa-Guinda, até valores anômalos de 130 metros conforme verificado na pesquisa da Lavra Boa Vista, no Campo de Extração (Tabela 1).

O Conglomerado Sopa típico é sustentado pelo grão, com clastos de quartzo, filito, filito hematitico, itabirito e rochas metavulcânicas ácidas. $\mathrm{O}$ tamanho destes pode variar de alguns milímetros até mais de um metro, como característico na Lavra de Boa Vista (Campo de Extração). A matriz também é variável de um campo para outro, de pelítica até arenosa média, assim como o teor em diamantes. Estas modificações devern representar apenas a distância da área-fonte ou o retrabalhamento marinho dos corpos conglomeráticos (Chaves, 1991a); estudos detalhados para posicionar os conglomerados dentro do ambiente de leque aluvial estão em andamento. Os teores em diamante são geralmente baixos, variando entre cerca de 0,07 $\mathrm{ct} / \mathrm{m}^{3}$ no Campo de Extração, até $0,01 \mathrm{ct} /$ $\mathrm{m}^{3}$ no Campo de Sopa-Guinda (Tabela 1). 
Tabela 1 - Principais parâmetros de comparação entre os conglomerados diamantíferos das formações Sopa Brumadinho (Mesoproterozóico) e Uberaba (Cretáceo Superior), Minas Gerais, segundo Chaves \& Svisero (1992).

\begin{tabular}{|c|c|c|c|c|c|}
\hline \multirow{2}{*}{\multicolumn{2}{|c|}{$\begin{array}{l}\text { Caracteristicas dos } \\
\text { conglomerados }\end{array}$}} & \multirow{2}{*}{$\begin{array}{l}\text { Formaçå̀o } \\
\text { Uberaba }\end{array}$} & \multicolumn{3}{|c|}{ Formaçăo Sopa-Brumadinho } \\
\hline & & & Guinda & Extração & Datas \\
\hline \multicolumn{2}{|c|}{ Forma dos corpos } & lenticular & lenticular & $\begin{array}{l}\text { lenticular e } \\
\text { acanalada }\end{array}$ & lenticular \\
\hline \multicolumn{2}{|c|}{ Espessura max. (m) } & 16 & 12 & $130(8)$ & 15 \\
\hline \multirow{3}{*}{ Clastos } & Classificaçăo & polimitico & polimítico & polimitico & polimítico \\
\hline & Selecionamento & $\begin{array}{c}\text { mal } \\
\text { selecionado }\end{array}$ & $\begin{array}{c}\text { mal } \\
\text { selecionado }\end{array}$ & $\begin{array}{c}\text { mal } \\
\text { solecionado }\end{array}$ & $\begin{array}{c}\text { mal } \\
\text { selecionado }\end{array}$ \\
\hline & $\begin{array}{l}\text { Tamanho máximo } \\
\text { (m) }\end{array}$ & 0,8 & 0,8 & 1,0 & 0,6 \\
\hline \multirow[t]{2}{*}{ manciomat } & Suporte & $\begin{array}{c}\text { clasto- } \\
\text { sustentado }\end{array}$ & $\begin{array}{c}\text { clasto- } \\
\text { sustentado }\end{array}$ & $\begin{array}{c}\text { clasto- } \\
\text { sustentado }\end{array}$ & $\begin{array}{c}\text { clasto- } \\
\text { sustentado }\end{array}$ \\
\hline & Arredondamento & subangulosos & subarredondados & subangulosos & subarredondados \\
\hline \multicolumn{2}{|c|}{ Matriz predominante } & argilosa & arenosa & argilosa & arenosa \\
\hline \multicolumn{2}{|c|}{ Teor médio em diamante $\left(\mathrm{ct} / \mathrm{m}^{3}\right)$} & $0,033-0,069$ & $0,039-0,015$ & $0,076-0,044$ & 0,042 \\
\hline
\end{tabular}

Poucos trabalhos se referem à mineralogia da matriz do Conglomerado Sopa. No tocante aos minerais pesados, análises preliminares isoladas de alguns concentrados de São João da Chapada (Lavra do Campo Sampaio) revelaram a presença de magnetita, hematita, goethita, rutilo, anatásio, fosfatos (diversos) e hornblenda. No campo de Datas, são tipicas as pseudomorfoses de pirita para limonita. Nenhum mineral de natureza possivelmente kimberlítica, no entanto, como na Mina de Romaria, foi encontrado até o presente momento.

\section{A PROVÍNCIA DIAMANTÍFERA DO ALTO PARANAíBA}

A natureza tectônica peculiar da região do Alto Paranaiba, constituindo um bloco alto na borda norte da Bacia do Paraná e integrando também a zona terminal (sul) da Faixa Brasilia, resultou em um arcabouço complexo, permitindo uma série de controvérsias a respeito das colunas es- tratigráficas propostas para a área. Discussão mais pormenorizada sobre essa questão pode ser encontrada em Chaves (1991b).

Embora as ocorrências de diamantes da Provincia do Alto Paranaiba sejam conhecidas desde o final do século dezoito, sua origem ainda é controvertida. Alguns autores advogam a existência de kimberlitos/lamproitos na região (Svisero et al., 1979; Barbosa, 1991; Leonardos et al., 1991); outros relacionam esse diamante, a transporte glacial de fontes situadas no Cráton do São Francisco a leste (Tompkins \& Gonzaga, 1989). Sabe-se que uma intrusão situada na Fazenda Alagoinha, próximo de Três Ranchos, Goiás, contém microdiamantes, mas faltam dados sobre esse e outros possiveis kimberlitos férteis da região. $\mathrm{Na}$ área de Romaria-Estrela do Sul, os diamantes estão relacionados aos conglomerados da base da Formação Uberaba, constituindo depósitos formados em leques aluviais (Suguio et al., 1979), conforme observa-se nas frentes de lavra da Mina de Ro- 
maria, presentemente desativada.

Na regiāo de Romaria-Estrela do Sul, o embasamento é formado por micaxistos, quartzitos e anfibolitos pertencentes ao Grupo Araxá (Mesoproterozóico?), ocupando as áreas mais baixas recortadas pelo Rio Bagagem. Em faixa restrita a oeste da Mina de Romaria, seguindo para sul, afloram arenitos puros e bem selecionados, provavelmente eólicos, atribuídos à Formaçăo Botucatu (Triássico-Jurássico). São as ocorrências mais ao norte conhecidas desta unidade, que possuem ai caracteristicas peculiares como intercalações locais de niveis brechosos pouco espessos que sugerem contribuição externa à bacia, talvez prenunciando a emergência da atividade tectônica relacionada ao Cretáceo. A Formação Uberaba, estratigraficamente acima (Cretáceo Superior), ocupa as porçôes mais altas do relevo, formando superficies de chapadas com grandes extensōes como ao norte de Romaria (Fig. 3).

\section{OS CONGLOMERADOS DA ÁREA DE ROMARIA}

No distrito de Romaria-Estrela do Sul (Fig. 3) os principais depósitos diamantíferos eståo relacionados ao conglomerado basal do Grupo Bauru (Formacăo. Uberaba), conhecido na região como "Tauá e bem representado principalmente na jazida de Romaria. Este depósito vem sendo explorado, intermitentemente, desde meados de século passado, com os conglomerados repousando em discordância sobre os micaxistos do Grupo Araxá e/ou sobre os arenitos eólicos da Formação Botucatu, conforme demonstrado em seções geológicas detalhadas por Feitosa \& Svisero (1984).

A sucessão estratigráfica da Formação Uberaba na área próxima a Romaria pode ser assim resumida (Svisero et al., 1981): na base, ocorrem os conglomerados

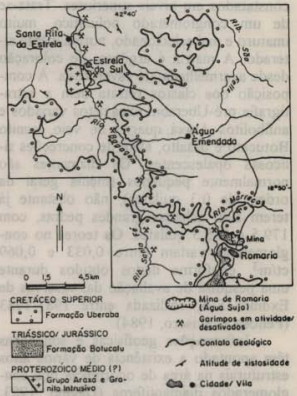

Figura 3 - Geologia e depósitos diamantíferos da regiāo de Romaria - Estréla do Sul.

diamantiferos típicos, com até cerca de 10 metros de espessura e clastos de grande porte. Sobreposto, aparece um conglomerado mais homogêneo, também polimítico mas com seixos menores (normalmente de porte centimétrico) e de espessura em torno de 3 metros (localmente denominado "Estrelado"). Acima destes, ocorrem arenitos grossos até finos e com intercalaçōes conglomeráticas. A matriz tem caracteristica coloração esverdeada, normalmente considerada como de origem tufăcea. A espessura deste pacote oscila em torno de 15 metros. Fechando o ciclo sedimentar, aparece um conglomerado oligomitico de matriz arenosa e seixos centimétricos bem arredondados, com espessura de cerca de 5 metros.

A ocorrência de diamantes na área está associada principalmente ao conglomerado "Tauá", embora já tenham sido 
constatados em niveis superiores. Trata-se de um conglomerado polimitico, muito imaturo e mal selecionado, normalmente alterado. A matriz é argilosa, de coloração desde avermelhada até esverdeada. A composição dos clastos retrata bem a estratigrafia pré-Uberaba: micaxistos variados e anfibolitos Araxá, quartzo de veio, arenito Botucatu e basalto, além de concreções silicosas opalescentes. Os diamantes são normalmente pequenos (média geral da ordem de 0,3 quilates), não obstante já terem sido achadas grandes pedras, com 179,5 e 105,5 quilates. Os teores no conglomerado variam entre 0,033 e 0,069 $\mathrm{ct} / \mathrm{m}^{3}$, conforme dados obtidos durante uma pesquisa de avaliação das reservas da Exdibra S/A, realizada entre 1981-1983 (Feitosa \& Svisero, 1984)

Informações geofisicas e sondagens têm apontado a existência de vários altos estruturais na área de ocorrência dos conglomerados diamantiferos (Davino, 1983; Feitosa \& Svisero, 1984). Estes altos do embasamento controlaram feiçōes dos conglomerados, como espessura, tamanho dos clastos, frequeência de minerais pesados e, conseqüentemente, teor diamantifero. Tais fatos indicam que as fontes dispersoras primárias estão estreitamente relacionadas a estes altos, apesar de na maior parte, provavelmente, já estarem erodidas. As feiçōes apresentadas pelos conglomerados evidenciam altas energias de transporte envolvidas em sua deposição, indicando, provavelmente, depósitos do tipo leques aluviais originados em clima semi-árido (Suguio et al., 1979).

Estudo dos concentrados obtidos durante a recuperação do diamante mostrou que o conglomerado contém, entre os minerais pesados, por volta de $95 \%$ de fases opacas incluindo magnetita, hematita, ilmenita, goethita e limonita, e diversas fases transparentes tais como diamante, zircão, granada, estaurolita, turmalina, rutilo, monazita, hornblenda, cianita e anatásio (Feitosa \& Svisero, 1984). As granadas pertencem a duas paragêneses distintas. 0 tipo mais comum é representado por cristais de coloração vinho a violácia de até $10 \mathrm{~mm}$, constituídos pelas moléculas piropo e knorringita (Svisero, 1979). Além da composição, a forma abaulada e a textura da superficie são características de granadas de kimberlitos. Em adição, exibem evidências de que foram pouco transportadas. Um segundo grupo de granadas são constituídas de almandina e grossulária, derivadas dos micaxistos do Grupo Araxá. Analogamente, as ilmenitas também são de dois tipos distintos: um tipo magnesiano com teores de $\mathrm{MgO}$ variando em torno de $10 \%$ em peso, sendo derivadas possivelmente de kimberlitos, e um segundo tipo constituidas essencialmente de titânio e ferro, originadas de rochas do embasamento (Svisero \& Meyer, 1981).

Apesar dessas e de outras evidências, tais como dezenas de kimberlitos ou rochas parentais já descritas e a ocorrência periódica de grandes diamantes, muitos com quilatagem superior a $100 \mathrm{ct}$ - todas indicadoras de rochas-fonte mineralizadas próximas - alguns autores como Tompkins \& Gonzaga (1989) admitem que o diamante do oeste de Minas Gerais provém de geleiras pré-cambrianas (glaciação Jequitai) desenvolvidas a norte da região.

\section{PALEOAMBIENTES DE SEDIMEN- TAÇÃO - ASPECTOS GERAIS}

Do ponto de vista morfológico e de estruturas sedimentares, são evidentes as semelhanças entre os dois tipos de conglomerados: 1) clastos de grande porte que em alguns casos chegam a dimensões de matacões; 2) grande diversidade de componentes; 3) contato basal erosivo; 4) espessuras análogas, etc. (Tabela 1).

Tem-se demonstrado também que os 
conglomerados Sopa e de Romaria possuem uma gênese bastante similar. Ambos são depósitos torrenciais, do tipo leque aluvial, caracteristicos de clima semi-árido em região tectonicamente instável. A atividade tectônica deve ter permitido o rápido soerguimento das áreas-fontes, ocasionando a erosão de muitas centenas de metros de rochas. Grossi Sad (1970) argumenta que cerca de 3000 metros de cobertura rochosa foi removida desde a intrusão dos grandes complexos alcalinos do Triângulo Mineiro, geralmente considerados contemporâneos das intrusões ultrabásicas em que se incluem as rochas kimberliticas do Alto Paranaiba. Desta maneira, as fácies mineralizadas das matrizes primárias do diamante podem ter sido removidas e seus minerais largamente distribuidos nos depósitos secundários (Chaves, 1991b).

As demais litologias das formações Sopa Brumadinho e Uberaba sảo constituidas principalmente por arenitos médios, grossos e conglomeráticos, típicos de ambiente fluvial. Certamente os leques aluviais, em suas porçōes distais, amalgamaram-se aos depósitos arenosos, levando ainda alguns diamantes até grandes distâncias. Esta premissa pode explicar o fato de existirem certas drenagens (atuais) diamantiferas, em locais onde aparentemente faltam os conglomerados.

Nos conglomerados da região de Romaria, como já foi destacado, ocorrem minerais típicos de kimberlitos, tais como piropos cromiferos e ilmenitas magnesianas. Para a -região de Diamantina, onde esses minerais não existem ou ainda não foram detectados, pretende-se iniciar um estudo sistemático dos acompanhantes do diamante na matriz do Conglomerado Sopa, nos principais campos diamantiferos conhecidos.

\section{CONSIDERACỖS FINAIS}

A gênese do diamante no Brasil tem sido desde longa data objeto de apaixonadas discussōes, em função de não serem ainda conhecidas as rochas matrizes deste mineral. Romaria e Diamantina representam duas ocorrências importantes de diamante detrítico no Brasil, notáveis pelo intervalo do tempo que separa seus depósitos (secundários) mineralizados.

As caracteristicas sedimentológicas, porém, indicam que os depósitos diamantíferos em Romaria e Diamantina formaram-se de maneira semelhante a partir de leques aluviais, o que também indicaria, $a$ priori, fontes primárias relativamente próximas e em rápido soerguimento. O estágio da formação e história de preenchimento da bacia também foi aproximadamente o mesmo para o posicionamento dos conglomerados em ambos os locais, isto é, associados a episódios de rejuvenescimento tectônico.

Em Romaria, ocorrem minerais satélites indicadores de kimberlitos (piropo cromífero, ilmenita magnesiana e cromo espinélio); em Diamantina esses indicadores estão ausentes, ou pelo menos não foram observados até o presente momento.

Com relação ao diamante, existem certas diferenças entre os dois locais. $\mathrm{Na}$ Mina de Romaria não há registros de grandes diamantes, mas no Rio Bagagem, que drena a área, é comum o aparecimento de pedras maiores, muitas vezes com mais de 50 quilates. Na regiăo de Diamantina as pedras raramente ultrapassam 5 quilates. Outra diferença é a relação gema/indústria; em Romaria ela é da ordem de $60 \%$ enquanto em Diamantina é de quase $90 \%$. Ainda característico da região de Diamantina é uma alta incidencia de pedras em torno de 0,5 a 2 quilates, que são exatamente as de interesse gemológico.

Essas diferenças e os fatos geológicos demonstrados servem para reforçar a hipótese de que houve pelo menos duas 
idades de magmatismo tipo "kimberlitico" (Cretáceo Superior e Mesoproterozóico), contrariando os argumentos de Tompkins e Gonzaga (1989) de que todo diamante que ocorre nas cercanias do Cráton São Francisco é pré-cambriano. Uma tectônica muito ativa (classicamente conhecida pelo menos no período cretácico) pode ter permitido a alocação dos corpos intrusivos, sejam eles kimberlíticos, lamproíticos ou de natureza ainda não conhecida, e a erosão subsequiente ter removido e dispersado as partes apicais mineralizadas das intrusões para as rochas conglomeráticas geradas na sequência do processo.

\section{REFERÊNCIAS BIBLIOGRÁFICAS}

BARBOSA, O. (1981) O diamante no Brasil: histórico, ocorrência, prospeccão e lavra. Brasilia, CPRM. 146p.

CHAVES, M.L.S.C. (1991a) Paleogeographic studies of the diamond-bearing Sopa Conglomerate in the Diamantina region (Minas Gerais), Brazil. In: INTERNATIONAL KIMBERLITE CONFERENCE, 5., Araxá, 1991. Extended Abstracts. Brasilia, CPRM. p.40-41.

CHAVES, M.L.S.C. (1991b) Sequêencias cretácicas e mineralizaçð̋es diamantiferas no Brasil Central e África CentroMeridional: considerações preliminares. Geociências, 10:231-245.

CHAVES, M.L.S.C.; DOSSIN, I.A.; UHLEIN, A; ALVARENGA, C.S.J. (1985) Projeto Mapeamento Geológico do Espinhaço Meridional. Diamantina, DNPM/CPRM/UFMG/CGE. 62 p. (Relatório da Quadrícula Sopa).

CHAVES, M.L.S.C.; SVISERO, D.P. (1992) Conglomerados diamantiferos da região de Romaria (Cretáceo Superior) e do Distrito de Diamantina (Proterozóico Médio): uma gênese semelhante? In: SIMPÓSIO SOBRE AS BACIAS CRETÁCICAS BRASILEIRAS, 2., Rio Cla- ro, 1992. Resumos Expandidos. Rio Claro. p. 126-128.

CHAVES, M.L.S.C.; UHLEIN, A. (1991) Depósitos diamantíferos da região do Alto/Médio Rio Jequitinhonha, Minas Gerais. In: SCHOBBENHAUS, C ; QUEIROZ, E.T.; COELHO, C.E.S. (coords.). Principais depósitos minerais do Brasil. Brasilia, DNPM. v.4-A. p. 117-138.

DAVINO, A. (1993) Configuração topográfica preterrita à sedimentação da Formação Uberaba na região de Romaria, Estrela do Sul e Monte Carmelo (MG). Revista Brasileira de Geociências, 13: $37-40$.

DOSSIN, LA.; DOSSIN, T.M.; CHAVES, M.L.S.C. (1990) Compartimentação estratigráfica do Supergrupo Espinhaço em Minas Gerais - os grupos Diamantina e Conselheiro Mata. Revista Brasileira de Geociências, 20:178-186.

FEITOSA, V.M.N.; SVISERO, D.P. (1984) Conglomerados diamantiferos da região de Romaria, MG. In: CONGRESSO BRASILEIRO DE GEOLOGIA, 33., Rio de Janeiro, 1984. Anais. Rio de Janeiro, SBG. v.10, p.49955005

FOGAÇA, A.C.C.; ABREU, P.A.A. (1982) Depósitos de planícies de marés na Formação Sopa-Brumadinho (Proterozóico Inferior), Cordilheira do Espinhaço, Estado de Minas Gerais, Brasil. In: CONGRESSO LATINO-AMERICANO DE GEOLOGIA, 5., Buenos Aires, 1992. Actas. Buenos Aires. v.2, p.373-388.

GARCIA, A.J.V ; UHLEIN, A. (1987) Sistemas deposicionais do Supergrupo Espinhaço na Região de Diamantina (MG). In: SIMPÓSIO SOBRE SISTEMAS DEPOSICIONAIS NO PRÉ-CAMBRIANO, 1, Ouro Preto, 1987. Anais. Ouro Preto, Núcleo de Minas Gerais, SBG. p.113-135. 
GROSSI SAD, J.H. (1970) Complexos silicocarbonatiticos da região do Alto Paranaíba, Brasil Meridional. In: CONGRESSO BRASILEIRO DE GEOLOGIA, 24., Brasilia, 1970. Resumo das conferências e comunicações. Brasilia, SBG. p.16-19.

LEONARDOS, O.H: $\quad$ ULBRICH, M.N.C.; GASPAR, J.C. (1991) The Mata da Corda Volcanic rocks. In: INTERNATIONAL KIMBERLITE CONFERENCE, 5., Araxá, 1991. Extended Abstracts. Brasilia, CPRM. p.65-73 (Special Publication, 3/91).

PFLUG, R. (1965) A geologia da parte meridional da Serra do Espinhaço e zonas adjacentes, Minas Gerais. Boletim Divisão de Geologia e Mineralogia. DNPM, (226): 1-55.

SUGUIO, K.; SVISERO, D.P; FELITTI FILHO, W. (1979) Conglomerados polimíticos diamantiferos de idade cretácea de Romaria (MG): um exemplo de sedimentação de leques aluviais. In: SIMPÓSIO REGIONAL DE GEOLOGIA, 2., Rio Claro, 1979. Atas. Rio Claro,
Núcleo de São Paulo, SBG. v.1, p.217229.

SVISERO, D.P. (1979) Piropos cromiferos da mina de diamantes de Romaria: composição química e origem. Boletim Mineralógico, (6): 7-14.

SVISERO, D.P.; FELITTI FILHO, W. ALMEIDA, J.S. (1981) Geologia da mina de diamantes de Romaria, MG. Mineração e Metalurgia, (425):4-14

SVISERO, D.P.; HASUI, Y. DRUMOND, D. (1979) Geologia de kimberlitos do Alto Paranaiba, Minas Gerais. Mineraçāo e Metalurgia, (406):34-38.

SVISERO, D.P.; MEYER, H.O.A. (1981) Ilmenitas kimberlíticas da mina de diamantes de Romaria, MG. Revista Brasileira de Geociências, 11:217-221.

TOMPKINS, L.A.; GONZAGA, G.M. (1989) Diamonds in Brazil and a proposed model for the origin and distribution of diamonds in the Coromandel region, Minas Gerais, Brazil. Economic Geology, 84:591-602.

ML.S.C.Chaves - Departamento de Geologia, IGCUFMG - Av. Antônio Carlos, 6627 CEP 31.270-010 Belo Horizonte, MG, Brasil.

D.P.Svisero - Departamento de Mineralogia e Petrologia, Instituto de Geociências/USP - Caixa Postal 11.348 CEP 05422-970 Såo Paulo, Brasil. 